\title{
Ethical criteria when a (potential) perpetrator asks a human rights organization to defend their case based on the forensic documentation of alleged torture. How shall we proceed?
}

\author{
Sara López Martín*
}

\section{Objective}

Discuss the ethical dilemma of perpetrators requesting clinical evaluations intended to prove persecution or torture. The discussion is organized around three real cases.

\section{Method}

We present three cases of plausible perpetrators, partially amended to protect anonymity. The paper presents a review of the complex ethical challenges that the dilemma poses.

A multidisciplinary panel of doctors, psychologists and lawyers had a similar discussion and agreed on three criteria presented here for contrast with the broader community of researchers and practitioners. The paper is not in itself a legal or ethical academic review, instead, it establishes the main terms of debate, demonstrates the lack of literature that debates it and reflects an initial consensus between forensic workers in an independent human rights organization.
^) Lawyer, SiRa, Madrid.

Correspondence to: juridico@redsira.net
Keywords: Torture, Medical Ethics, Perpetrators, Istanbul Protocol

\section{Introduction}

This paper aims to explore issues to be considered when defendants, who have allegedly committed torture, request independent forensic documentation to support their claim for asylum.

The discussion arises from a multidisciplinary team at an NGO, whose primary mission is to provide supporting documentation for asylum claims made by victims of torture, using the Istanbul Protocol. This discussion is part of our process for developing policies and guidelines for our daily work. The enormous increase of asylum applications in southern European countries, in addition to the changing national contexts where our patients come from, has led us to assess several persons who could be both a survivor of torture as well as a possible perpetrator of torture.

The current academic discussion on the subject appears to be focused on ethical duties during judicial forensic investigations (Adshead \& Sarkar, 2020; Goethals, 2018; Mason, 2006; Niveau \& Welle, 2018), an ac- 
tivity regulated by labour legislation - which limits ethical decision making - and of which ultimately does not apply to a pro-bono human rights NGO. Furthermore, the focus seems to be on identifying decision-making standards rather than on the ethical sense of the options themselves.

Three semi-fictional cases are presented and discussed to expose ethical dilemmas. We look forward to reactions from other experts facing similar dilemmas.

\section{Case 1}

Georgia - A middle-aged man serving in high-ranking military positions to face proRussian military actions. Following a change of government, he resigned. There are criminal proceedings against senior leaders of the government he served that do not directly involve him. However, human rights organizations have reported crimes against humanity in several areas where troops under his command were involved. $\mathrm{He}$ attributes an arrest warrant against him to political persecution by the new government, on account of his nationalist affiliations.

In fact, after his resignation, he was arrested by his government and interrogated for nine days. He reports being beaten, subjected to sleep deprivation and threatened with death. After release, he eluded surveillance and left the country.

Clinical and psychometric examination revealed intrusive post-traumatic symptoms, frequent episodes of anger, impaired concentration, hypervigilance, hyper-reactivity and anxiety to unexpected stimuli. He was diagnosed with complex PTSD. His reports of being tortured were found to be credible and moderately consistent.

\section{Case 2}

Colombia - A young man from a country with prolonged conflict between the state and "guerrillas". When he was 18 years old, he was captured by an armed group which he then joined. During the seven years that he was with that group, various human rights groups identified them as being responsible for perpetrating torture and massacring peasants. The massacre is currently the subject of a criminal trial.

During a peace process, he left the group, moved to another state and attempted to hide. Two years later, the group located him and kidnapped him again. He was taken to a flat where he was beaten and raped by five men whom he recognised as former colleagues. After four days, he was left in a field. Following this, he fled the country immediately.

One year after his arrival, he was referred to our centre by the NGO that was managing his asylum application. That NGO requested a psychiatric assessment after their initial assessment identified symptoms of post-traumatic stress disorder. His symptoms included suicidal ideation, shame and guilt, low self-esteem, angry outbursts, and difficulty with memory and dissociation when talking about his experiences. Our centre diagnosed partial remitted post-traumatic stress disorder and found his report of being abused to be moderately consistent.

\section{Case 3}

Brazil - A young man worked for three years as an informant for a police unit specialised in criminal gangs. After one gang member recognised him, he subsequently received death threats at home and was shot by motorcyclists whilst driving. Thereafter, he experienced fear and intense anxiety, hypervigilance, pronounced startle reactions and difficulty sleeping. He moved several times to different parts of the country but was again identified, shot in the chest and legs, and dropped in a ditch. 
After several weeks in the hospital, he left the country. He applied for asylum and was referred to our centre.

When studying the case, the legal team discovered that reports from human rights organizations labelled the police unit he previously worked for as a para-police squad. He stated that he only "provided information" to special police undercover units to capture "thieves" and "leftist terrorists." He continues to cooperate with the unit from a distance and showed our staff photographs he has recently sent via WhatsApp of potential targets. He has also told our interviewers about a song in which, he says, an anonymous voice describes how he will be tortured when located.

The patient does not appear to have post-traumatic symptoms, apart from sporadic distressing dreams. Although the account of torture is considered consistent, he has no clinical diagnosis. He seems to be a resilient person, although he may have a well-founded fear of torture if returned to his country of origin.

Table 1. Ethical dilemmas

\section{Main Ethical decision/ First Order Dilemma}

- Dilemma 1. Should a pro-bono NGO do a forensic assessment, of a highly probable perpetrator that alleges to have been tortured him/herself, to claim for international protection?

\section{Second order ethical dilemmas - dealing with the past}

- Dilemma 2a. Should we, as an institution, “judge” our client's behavior? Are we circumventing the presumption of innocence? Is the role of a forensic expert that of a "judge" to decide whether a potential client is a "perpetrator"?

- Dilemma 2b. In forensic assessments of clients, do we have the duty to triangulate information to assess consistence and credibility? What are the limits of the "triangulation of information" mandate? Morally, how far can we go in knowing the client's whereabouts?

- Dilemma 2c. By cross-checking information with human rights organizations in the client's country of origin, we may put the client in danger, thereby violating the "dono-harm" principle of any health intervention.

- Dilemma $2 \mathrm{~d}$. If the alleged perpetrator has post-traumatic symptoms, is there an ethical duty to care?

\section{Third order ethical dilemmas - facing the present}

- Dilemma 3a. The client may still be involved in present-day heinous acts - by protecting him, the organization may facilitate human right violations

- Dilemma 3b. The client may be under national or international prosecution - by protecting him, the organization may prevent victims' access to justice or reparation

\section{Fourth order ethical dilemmas - Reason for claiming asylum}

- Dilemma 4a. Not documenting the client's allegations might mean that the person is deported to the country of origin and eventually face further torture or death. 


\section{Dilemmas}

As Swanepoel (2010) points out, "Making ethical or moral decisions, like any other decision in health care, is not a precise art but a learned skill. What decision is ultimately made and how that decision is made has always been the topic of intense debate". Table $\mathbf{1}$ is a proposed map of the dilemmas of these cases.

First Order Dilemmas (Accepting clients who are survivors and perpetrators of torture).

Should a centre providing services to torture survivors undertake a forensic assessment of suffering torture survivors, when it has reason to believe that the potential client has been complicit in torture? Here we have our main ethical decision. The Convention Against Torture Convention against Torture and Other Cruel, Inhuman or Degrading Treatment or Punishment (1984) does not void the rights of a torture survivor in any case, including torturers. However, the staff of a rehabilitation centre, especially those who have survived torture, may be reluctant to work with torture survivors who have, themselves, tortured. However, our main problem is defining the institution's "political" approach to this issue. Here we have to consider the sub-dilemmas that underlie this debate.

Second Order Dilemmas (Studying the case).

Secondly, and as second-order ethical dilemmas (dilemmas $2 a$ and $2 b$ in Table 1 ), there is the question of whether our organization may judge the acts and motivations claimed by the client who admits to being complicit in torture. As a starting point, we do not want to dispute the veracity of torture allegations our job consists precisely in determining the credibility, among other issues, of the allegations - made by our hypothetical patients. We also know that criminal responsibility for what a torturer has done is not excused simply because such a person was subsequently tortured.

However, trust is a necessary pre-condition to work on the forensic assessment of an alleged victim. Moreover, trust and confidence are complex matters assuming our impartiality, but also our commitment to the absolute prohibition of torture. Since we systematically triangulate the information provided in the interviews with clients, are we morally allowed to investigate our patients in those aspects not related to their torture experience as a victim? Such documentation policies strike at the heart of potential clients' need to trust the centre as they seek help for the injuries of torture. Do we become our patients' "investigators" or "prosecutors"? Furthermore, and in practical terms, what does it mean for us? Do we accept that we could endanger the safety of our patients if we request information from human-rights colleagues about them in their country of origin; especially, but not only, in cases of asylum seekers? (Dilemma 2c).

On the other hand, some of them have shown persistent post-traumatic symptoms. This leads us to wonder whether we can ignore the deontological duty to assist patients with severe impacts (CGCOM, 2011; CGCOP, 2010; International Rehabilitation Council for Torture Victims, 2012). (Dilemma 2d)

In some cases, the evidence might be relatively clear. Some clients, as in Case 1, might be under national or international prosecution for human rights crimes. How should global human rights reports be used to assess an individual's criminal responsibility? In Case 2 , for example, is it enough to know that the client was associated with a group that was notorious for human rights crimes, or should a more detailed assessment be made to assess personal complicity? 
Third Order Dilemmas (Addressing clients' ongoing complicity with torture, or future responsibility for torture in the past).

We could avoid dilemmas related to the past, but sometimes, as the examples illustrate, we are confronted with dilemmas related to the present and the future. Let us focus on them.

On the one hand, some clients, as in Case 3 , might still be involved in present heinous acts. In such cases, the centre may be seen as complicit with ongoing human right violations. Does a centre have a duty to retain, report, or discharge such clients? If our intervention means, and it does, to enable these people to obtain asylum in our country, it would be easy to conclude that by doing so, we would potentially be facilitating human rights violations (dilemma 3a).

Furthermore, some of our clients might have a claim from a national or international court (Case 1, who pointed out the possible existence of an arrest warrant against him, and Case 2, who could be claimed by the victims of the reported massacre). If our intervention in this involves allowing them to hide in our country, we would potentially be preventing their alleged victims from accessing reparation: we would become a masking identity machine for potential perpetrators. Can we afford that? We would act against our principles in helping to provide reparation to torture victims (dilemma $3 b$ ). We must assess this potential situation, pondering that, perhaps the client's testimony is true.

Inevitably, we are also concerned about the legal risks we may have to assume in protecting an alleged perpetrator, accused of potential human rights violations.

Fourth Order Dilemmas (Addressing the consequences of providing services to torture survivors who are torturers.)
Finally, a centre that services torture survivors must reflect on the consequences of servicing clients who are also torturers. If asylum is denied because the centre uncovered complicity with torture, the client may be placed in grave danger upon returning to their country of origin. We cannot ensure that these people would be brought before a judge, entitled to fundamental rights and guarantees, nor can we guarantee that they will not be tortured or killed shortly thereafter returning. Therefore, if the Istanbul Protocol is not implemented, we may be cooperating in the death or torture of our potential client (dilemma $4 \mathrm{a}$ ).

Authorities agree that there is no duty to refoul when there are "substantial grounds" for believing that the person would be in danger of being tortured. France (Le Monde, 2011; Radio France Internationale, 2014) and England (Government of Rwanda v. Nteziryayo, Brown, Munyaneza, Mutabaruka \& Ugirashebuja, 2017) refused to extradite persons accused of torture after ruling that Rwanda did not meet the requirements of Rule 11 bis. However, Article 33(2) of the 1951 Convention Relating to the Status of Refugees (1951) allows deporting asylum applicants who pose a risk to national security. Needless to say, we have witnessed the deportation of applicants, despite awareness that we, and any sensible citizen, know they will be tortured upon return. Therefore, not implementing Istanbul Protocols may mean cooperating in the death or torture of our potential client (dilemma 4a).

Thus, our dilemma is not a legal one, but instead an ethical one. Is it possible to assume this, individually and collectively? Should we find out if they have any court claims, or if they have been convicted? Do we have an obligation as NGOs to investigate if there is a suspicion? Can we make proper ethical decisions about these matters? 
We know that we must assess and rehabilitate survivors of torture and that we have no professional obligation to lie about a client's background. However, simultaneously, we can certainly decide what and how to ask, including what to avoid particularly when we foresee the course of the answer. It should not be forgotten that we sign a confidentiality agreement with the client before conducting the interviews, allowing a climate of trust and confidence. Should we denounce our patients if our suspicions turn out to be accurate or we hear something that we know can determine the rejection of asylum in that case? Being a perpetrator or prosecuted for criminal charges is a ground for exclusion from international protection according to Rule 33.2 of the 1951 Geneva Convention.

\section{Discussion and proposed criteria for moving forward}

There are no guidelines for accepting or managing the torture survivor who is also a torturer. Although scholars have extensively analysed the dilemmas faced by professionals in psychiatry and forensic psychology in legal proceedings, the issues discussed in this paper arise from professional ethics. Our centre's multidisciplinary team searched for policy guidelines to guide decisions when a torture survivor is possibly a torturer.

Some authors use ethics principles or rules (Kalmbach, 2006); others refer to legal duties (Goethals, 2018). However, this paper is about ethics, not law. Some (Adshead \& Sarkar, 2020) analyse the ethics of particular treatment techniques without addressing the background issue of whether to accept a client in the first place. Some authors compile different professional forensic and medical criteria for decisions (Swanepoel, 2010; Yadav, 2017), but only propose a vague case-by-case decision-making process. A few authors propose integrated models of legal and medical duties called "robust professionalism" (Candilis, 2009) that advocate for a compassionate inquiry into clients' backgrounds and reason for becoming torturers.

To the extent that many of them have focused on specific aspects of professional practice, there are no general guidelines for reflection to be found amongst these sources, just because our field of action is subjected to distinct rules. Firstly, we are not obliged to accept all the cases referred to us or coming to our centre. Secondly, we are not obliged to provide expert reports if pre-established criteria in the team's methodology are not fulfilled. We could initially decide to do a report and then during the course of the interview, reverse our decision based on information that emerges. Thirdly, accountability is primarily performed before the client, and, if appropriate, his or her legal counsel. Only when required must we appear in court, and then it is exclusively our professional judgment that guides our intervention, as the independent entity we are. None of these issues are contemplated in the existing literature on ethical codes and principles in forensic, psychological or medical work.

Concerning the First Order Dilemmas, we will not exclude all potential clients who were torturers and subsequent torture survivors. In this situation, our first obligation is to the client. Our stance must be therapeutic, not judgmental. Therefore, this involves ensuring these clients receive equal treatment, especially when suspicious information is not sufficient to make a decision otherwise. Moreover, if our client, who is suspected of having tortured others, presents to us in a severe distressing condition, our deontological duty is to guarantee his stabilisation before attending to our mistrust. This decision cannot be imposed 
on staff who raise ethical objections; however we consider it to be a policy of the centre.

Given the above resolution of First Order Dilemmas, we proceed to the Second Order Dilemmas. Mason (2006) depicts how prejudices can be destroyed by proximity: "What comes across invariably is their raw humanity, their often blundering but impassioned existential endeavour to be in the world, more or less eclipsed by their maladaptive, injurious, and sometimes malevolent behaviour". Moreover, after so many years, we have realised that our usual positive prejudice towards victims of torture is not universal. It loses meaning if we are consistently committed to the fight against torture: unpleasant, dishonest, or worse, could also be tortured, which a priori would include the perpetrators of torture.

We concluded that we could not call into question the "presumption of innocence" we all deserve. Furthermore, it is not (nor should it be) our work to investigate clients' lives, except necessarily obtaining contextual verification and clarification on information provided by the client. We understand it is not a matter of logistical capacity, but instead an account of the consistency of our professional values. We have to choose whose side we work on, and working on the victim's side sometimes requires assumptions such as that the victim may be lying, or not telling the entire truth. They may be a perpetrator of torture, in which case we are unable to investigate beyond searching online for their name. At the same time, choosing this framework implies the understanding that the victim who takes priority, is that who is in front of us. Otherwise, we would be assuming "ticking-time-bomb" logic (placing hypothetical scenarios before the real ones), with which we do not agree.

We consider, moreover, that any ethical commitment of this nature also requires, as a starting point, ensuring the safety of our clients. Requesting information about them from officials in their country of origin, or human rights groups could endanger the client (either as a torture survivor or as a torturer) by revealing his or her location.

Concerning Third Order Dilemmas, where the client, as in Case 3 (dilemma 3a), has continued to collaborate with organizations who are torturing, we propose discharging such clients on certain bases. These bases are where there is conclusive evidence or a personal statement indicating current involvement with human rights violations. Only in these cases, and not through active research on our part, would we make this decision.

The term "active perpetrators" is an ill-defined term. However, the mere persistence of a client's connection to identifiable structures engaged in human rights violations poses us an additional dilemma. This dilemma regards an assurance that our work does not become a potential risk to others, such as other patients or people who coexist with the potential perpetrator. We understand that, in these cases, we are not considering potential or hypothetical damage to third parties. However, an actual and verifiable situation of the client's involvement whereby such clients pose a potential risk to others, including both clients and non-clients (regarding asylum seekers, the public reception system concentrates them in a few entities throughout the territory, thus facilitating the meeting of applicants from confronted groups of the same nationality, which would lead to possible harmful interactions), as well as centre staff. This policy is supported, as Yadav (2017) notes, in ethical codes such as that of the Canadian Psychological Association's "Psychologists need to avoid or refuse to participate in practices contrary to the legal, civil or moral rights of others as well as refuse to assist anyone who might use a psychologist's knowledge 
to advise, train or supply information to anyone to violate human rights" (CPA, 2017).

The policy problem is more profound. Is there a duty to report such ongoing collaboration, and if so, to whom and how? Some ethical guidance arises from "duty to E" literature as reviewed by Ford \& Rotter (2014) stipulating that disclosure is required if the threat is specific and the victim is not aware of the danger (Tarasoff v. Regents of University of California, 1976). However, most of this information is non-specific. The World Psychiatric Association mentions, albeit fails to provide sufficient detail on how reports of this nature should be made. It notes, "Breach of confidentiality may only be appropriate when serious physical or mental harm to the patient or a third person would ensure if confidentiality were maintained" (1996), as does the United Nations in the Principles for the Protection of Persons with Mental Illness and the Improvement of Mental Health Care (United Nations, 1991). However, there is an additional concern - are we placing our team members at risk if we report it? Can we accept that possibility? These matters are left open.

Similarly, we suggest the possibility of rejecting a case if, according to the person's testimony or in the light of conclusive evidence not sought by us, the patient is being pursued through court (dilemma 3b). This is due to being inconsistent with hindering ones redress process, when presumably trying to facilitate another.
Inevitably, we are also concerned about the legal risks we may have to assume in protecting an alleged perpetrator, accused of potential human rights violations.

Finally, concerning Fourth Order Dilemmas, we have a customary obligation to honestly advocate on behalf of the interest of these complex clients. It is not our role to obstruct the pressing of criminal or civil charges against clients for their complicity with torture. It is our role to prevent refoulment in the face of a well-founded fear of torture or illegal persecution as described in Rule 33.2 of the 1951 Geneva Conventions and other international laws. Thus, when the possibility of deportation to one of these countries is dependent to some extent on our report, the need to guarantee the persons integrity would come first.

Given the nature of our clients' countries of origin, we concur with Swanepoel (2010) to act on a case-by-case basis. This means recognising that "[a]bsolute rules do not offer useful solutions to conflicts in values. What is needed is wisdom and restraint, compromise and tolerance, and an as wholesome respect for the dignity of the individual as the respect accorded the dignity of science" (Brim, 1965, p.1184).

These are our initial thoughts and reflections on this complex ethical dilemma. We are sure we have failed to take other essential aspects into account. The discussion is open for elaboration and refinement.

Table 2. Proposed criteria by the panel

1. Rejecting potential clients where there is conclusive evidence that they might be active perpetrators

2. Rejecting potential clients that are claimed by a national or international Court for human rights violations

3. Not contributing to the refoulment of anyone - perpetrator or not- to a country that will not guarantee their physical and psychological integrity. 


\section{References}

Adshead, G., \& Sarkar, S. P. (2020). Ethical Issues in Clinical Forensic Psychiatry. In A. Igoumenou (Ed.). Psychiatry, 6. https://doi.org/10.1007/9783-030-37301-6

Brim, O. G. (1965). Privacy and Behavioural Research. Columbia Law Review, 7, 1184 - 1211.

Canadian Psychological Association. (2017). Canadian Code of Ethics for Psychologists ( $4^{\text {th }}$ ed.). Canadian Psychological Association. https://cpa. ca/docs/File/Ethics/CPA_Code_2017_4thEd.pdf

Candilis, P. J. (2009). The Revolution in Forensic Ethics: Narrative, Compassion, and A Robust Professionalism. Psychiatric Clinics of North America, 32(2), 423-435. https://doi. org/10.1016/j.psc.2009.02.005

Consejo General de Colegios Oficiales de Psicólogos. (2010). Código Deontológico, Madrid. https:// www.cop.es/pdf/Codigo-Deontologico-ConsejoAdaptacion-Ley-Omnibus.pdf

Consejo General de Colegios Oficiales de Médicos. (2011). Código de Deontología Médica. Madrid. https://www.cgcom.es/sites/default/files/codigo_ deontologia_medica.pdf

Ford, E., \& Rotter, M. (2014). Landmark Cases in Forensic Psychiatry. Oxford University Press. https://doi.org/10.1201/b13499-98

Goethals, K. (2018). Forensic Psychiatry and Psychology in Europe: A Cross-border Study Guide. Springer International Publishing. https://doi. org/10.1093/med/9780199393435.003.0019

Government of Rwanda v. Nteziryayo, Brown, Munyaneza, Mutabaruka \& Ugirashebuja, [2017] EWHC 1912 (Admin). (2017). https://www. judiciary.uk/wp-content/uploads/2017/07/rwandav-nteziryayo-and-others-judgment-20170728.pdf

International Rehabilitation Council for Torture Victims. (2012). Forensic Examination Missions by Medical Teams Investigating and Documenting Alleged Cases of Torture: Operational Manual. International Rehabilitation Council for Torture Victims. https://irct.org/assets/uploads/ pdf_20161120160850.pdf

Kalmbach, K. C., \& Lyons, P. M. (2006). Ethical Issues in Conducting Forensic Evaluations. Applied Psychology in Criminal fustice, 2(3), 261-290.

Le Monde. (2011, 28 September). La Demande d'extradition d'Agathe Habyarimana Rejetee. Le Monde. https://www.lemonde.fr/afrique/ article/2011/09/28/la-demande-d-extradition-dagathe-habyarimana-rejetee_1579081_3212.html

Mason, T. (2006). Forensic Psychiatry: Influences of Evil. Humana Press.
Niveau, G., \& Welle, I. (2018). Forensic Psychiatry, One Subspecialty with Two Ethics? A Systematic Review. BMC Medical Ethics, 19(1), 1-10. https:// doi.org/10.1186/s12910-018-0266-5

OHCHR (1991) Principles for the Protection of Persons with Mental Illness and the Improvement of Mental Health Care, United Nations General Assembly Resolution 46/119. https://www.who.int/mental_health/policy/en/ UN_Resolution_on_protection_of_persons_with_ mental_illness.pdf

Radio France Internationale. (2014, 26 February). Top French Court Blocks Extradition of Rwandan Genocide Suspects. Radio France Internationale. https://www.rfi.fr/en/ africa/20140226-top-french-court-rules-againstextradition-three-rwandan-genocide-suspects

Swanepoel, M. (2010). Ethical Decision-Making in Forensic Psychology. Koers, 75(4), 851-872.

Tarasoff v. Regents of University of California, 17 Cal.3D 425. (1976). https://scocal.stanford. edu/opinion/tarasoff-v-regents-universitycalifornia-30278

UN General Assembly, Convention Against Torture and Other Cruel, Inhuman or Degrading Treatment or Punishment, 10 December 1984, United Nations, Treaty Series, vol. 1465, p. 85, available at: https://www.refworld.org/ docid/3ae6b3a94.html

UN General Assembly, Convention Relating to the Status of Refugees, 28 July 1951, United Nations, Treaty Series, vol. 189, p. 137, available at: https://www.refworld.org/docid/3be01b964. html

World Psychiatric Association. (1996). Madrid Declaration on Ethical Standards for Psychiatric Practice. https://www.ochrance.cz/fileadmin/ user_upload/ochrana_osob/Umluvy/zdravotnictvi/ Madrid_declaration_on_ethical_standards.pdf

Yadav, P. K. (2017). Ethical Issues Across Different Fields of Forensic Science. Egyptian fournal of Forensic Sciences, 7(1), 1-6. https://doi. org/10.1186/s41935-017-0010-1 